\title{
Sobre el significado de la palabra quechua manco y el nombre Manco Qhapaq ${ }^{1}$
}

\author{
Luis Arana-Bustamante \\ Universidad Nacional Mayor de San Marcos \\ laranab@unmsm.edu.pe
}

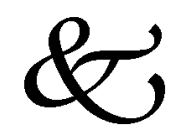

\begin{abstract}
Resumen
A partir de información sobre el término manco -obtenida de una hablante del quechua ayacuchano- en conexión a otras fuentes y a lo ahora conocido de la organización social de los inkas en el Cuzco, se analiza el posible significado del citado término quechua en relación a uno de los componentes del nombre y título del primer rey ancestro de la dinastía real inka, Manco Qhapaq.

Palabras claves: Manco; Manco Qhapaq; linguiística histórica quechua; mitos de origen de los inkas; Perú, siglo XV.
\end{abstract}

\begin{abstract}
From oral information about the word 'manco' provided by an informant and Quechua speaker from Ayacucho I connect here it with another sources -and current knowledge about social organization of Inka in Cuzco-for a proposed elucidation of the name as component of royal title of founder of royal Inka 'dinasty', Manco Qhapaq.

Keywords: Manco; Manco Qhapaq; Quechua historical lingüistics; Inka origins mithology Perú, XVth century.

Recibido: 5/1/15 Aceptado: 29/1/15 Publicado on line: 10/2/15

Manco es nombre propio: no sabemos qué signifique en la lengua general del Perú, aunque en la particular que los Incas tenían (la cual me escriven del Perú
\end{abstract}

1 Este artículo es parte de los resultados del proyecto 131501295 presentado al Instituto de Investigaciones Histórico Sociales (IIHS) de la Universidad Nacional Mayor de San Marcos. 
se ha perdido ya totalmente) devía tener alguna significación, porque por la mayor parte todos los nombres de los Reyes la tenían...

Garcilaso de la Vega, Comentarios, 1609, Libro I, cap. XXIV, 1943:58.

En diciembre de 2005 sostuve un diálogo en castellano en las afueras de Lima con la señorita Nelly Yutca -natural de Cangallo, Ayacucho, bilinguie y hablante del quechua de esa región- quien vino a Lima a los quince años. Me encontraba en ese entonces traduciendo los pasajes y términos quechuas de un manuscrito de origen colonial para una monografía (2010) y ella tuvo la bondad de ayudarme libremente. Se me ocurrió preguntarle además acerca de otros términos en quechua que son importantes para la historia y la historia de la religión de los inka -varios de los cuales no figuran en los diccionarios de origen colonial- pues su uso moderno no es conocido y por eso no tienen significado definido en los estudios de esta civilización. Le pedí además todos los datos de tipo directo y práctico, es decir 'funcional', sobre los términos que tuvo a bien proporcionarme.

Como me encuentro en este momento reexaminando para una investigación más amplia las versiones inka acerca de su propio origen social -la conocida mitología o mitohistoria de los hermanos Ayar-, he creído de interés reportar y comenzar con la discusión de algunos de los datos específicos que obtuve en aquella ocasión de la señorita Yutca, y luego exponer las correlaciones que podemos hacer y las conclusiones que podemos obtener de estos datos respecto al significado del nombre del primer ancestro de la pseudodinastía de los inkas, Manco Qhapaq.

\section{Significados obtenidos en el 2005}

Entre los términos quechuas cuya traducción obtuve de mi informante en aquella ocasión estuvo -para mi sorpresa- una definición muy precisa para la palabra manco, que ella definió en torno a la expresión "mancorakamusa", que tradujo como "hago un hueco (grande)" y precisó que se refería a la acción de hacer un hoyo muy grande en el suelo y escarbar -o cosechar- las papas. Preguntada al respecto, la hablante diferenció bien y opuso tal expresión a la más previsible de "uchkurakamusa", la cual tradujo como "hago un hueco pequeño”. Vinculándolas a ambas expresiones -y quizá por lo mismo- al preguntarle sobre la voz 'ayar' la asoció no -como uno podría imaginar- a los 'abuelos' o ancestros sociales sino a la expresión "ayarakamusa papata [o] maswata", traduciéndolas como "cosecho con herramienta papas o maswas". Al preguntársele por la herramienta a la que se refería describió el bastón cavador corto que se usa a este propósito en los Andes. 
Comenzando ahora el análisis con esta expresión, aya o ayar, la definición más extendida entre los especialistas se refiere a aya como muerto y también como ancestro o antepasado social. Esta última acepción -junto a voces como auilu o villca- está derivada de una característica de la cultura contemporánea de los Andes, el culto de los ancestros o antepasados sociales. El diccionario quechua colonial de Gonzáles Holguín (1608) restringe la acepción de aya a

Aya. Cuerpo muerto, o

Aya huaci, o hutcco. Sepultura [Gonzáles Holguín:39]

En realidad la acepción dada por la señorita Yutca de 'ayarakamusa' con referencia al palo cavador no se contradice a la acepción social en los Andes de aya como ancestro. Es conocido que en la cosmología nativa andina los primeros ancestros portan palos cavadores en la mayor parte de versiones de mitos de origen, y así se les observa en algunas representaciones prehispánicas. De hecho, pueden verse al respecto los dibujos en ceramios Nazca del Museo de Gotemburgo, Suecia, estudiados por Zuidema en 1972, donde se observan ancestros saliendo del inframundo por una gruta en forma de boca, caminando y cavando con delgados bastones ([1972]1989, fotos 10, 11 y 12). También puede verse la representación característica de la "primera generación de indios', uariuiracocha -también llamados pacarimoc runa- en la Nueva Corónica de Guaman Poma, ff. 47 y 48, donde se dice que "[c]omensaron a trauajar, arar...", pues “...esta gente no sauía hazer nada” -es decir provenía de un pasado precultural- y se les retrata trabajando la tierra (por primera vez, se deduce) con chaqitaqllas.

\section{El culto de los reyes-ancestro entre los inka. Un resumen}

Dado que el nombre Manco como componente del título del ancestro real se convierte en parte en 'nombre propio' -como dice Garcilaso en el epígrafe utilizado en este trabajo-, ahora nos encontramos en la necesidad de aclarar algunos aspectos del culto ancestral entre los inka. El culto a los ancestros es en general un rasgo propio de las cosmologías o religiones de las sociedades agrarias, dependientes de la tierra y de la posesión de los recursos del suelo, desde las tribus desarrolladas hasta los estados, pasando por las jefaturas. La abundancia de población de estas sociedades les exige la competencia por estos recursos, y una constante ansiedad por su posesión. En el caso de las élites el culto ancestral también involucra la adoración de los ancestros de la nobleza, que asegura a laa élites la posesión de las mejores tierras y el disfrute de sus privilegios sociales, sancionados en los mitos fundacionales 
por la jerarquízación de los ancestros mismos. En muchos casos estas sociedades conservaban los cuerpos momificados de los jefes y de los reyes, que preservaban así su importancia en la vida social. ${ }^{2}$

En el caso de los inkas es conocido el culto de los ancestros de los reyes, organizados en un sistema al que podemos calificar de pseudodinastía, que reducía el recuerdo social del número de reyes contabilizados al número esquemático de cinco reyes-antepasados, dispuestos en dos hileras frente a la del último rey reinante para su adoración conjunta en el Qorikancha. Esto totalizaba diez soberanos-ancestros, cinco para cada una de las mitades sociales o moietiés en que se dividía el Cuzco. Esta lista también podía leerse como de cinco reyes hurin antecediendo temporalmente a los cinco hanan. Como en todos los Andes, el culto se materializaba en la adoración de los cuerpos momificados, incluyendo libación y comida conjunta y renovación de los vestidos por los adoradores vivos de su grupo social. En el caso de los ancestros más antiguos, como Manco Qhapaq -primer ancestro de los inkas, surgido del inframundo según la narración mítica correspondiente- se adoraba un bulto que lo representaba. ${ }^{3}$

\section{El significado de manco en relación a Manco Qhapaq}

La mayor parte de especialistas no dan definición alguna para la voz manco, dado que no se encuentra en los diccionarios quechuas usados habitualmente. Sin embargo, Zuidema lo ubicó como 'manqhue' en el diccionario aymara de Bertonio y en un artículo interpretó esta voz tanto como 'cueva o profundidad para esconderse' -la definición de Bertonio- como 'fundador = P.P.P.P.', [es decir tatarabuelo] ([1980]1989:100,101). Años antes brindó a Rostworowski ([1969-70]1993:46) una referencia personal según la cual manco se referiría al tronco de una familia. Ambas definiciones pueden ponerse en relación a sus ideas sobre la ubicación de este rey-ancestro en la base de la mencionada estructura pseudodinástica paralela de los reyes ancestros inka propuesta por este autor (invirtiendo la situación de Manco Qhapaq como 'ancestro apical' del denominado Qhapaq ayllu y de la pseudodinastía real al mismo tiempo).

De hecho, consta en el diccionario de Bertonio:

Manqhue, vel mikayo. Profundidad o profundo del agua, tierra y otras cosas. (Bertonio, I:215)

Manqhue, kotayo, Toca [.] Cueva o profundidad para esconder (idem)

2 Ver una presentación del tema en términos amplios en Salomon (1991).

3 Hemos resumido aquí algunas características fundamentales del culto ancestral de los inkas, tratado numerosas veces por R.T. Zuidema en diferentes textos, que asumen este culto como una especie de hecho dado (p.ej. 1979, 1986). 
$y$, por otro lado e interesantemente,

Manqhue pacha, el infierno [aludiendo probablemente al inframundo] (idem).

En Bertonio tenemos también

Mancca. Abaxo (Bertonio, I:213)

Mancca pata uta, Casa que está más abaxo que otra (idem),

y nuevamente,

Mancca pacha: Infierno. Los de aquí [¿?] dizen, manqhue pacha (idem)

Esta presencia del término en este diccionario colonial aymara se explica por el origen del quechua de la región del Cuzco en una coalescencia de las lenguas aymara y quechua en la región en que se desarrolló el imperio de los inkas. Además es conocida ahora la coexistencia de las tradiciones estatales y culturales Tiwanaku y Wari en la región del valle del Cuzco desde mucho tiempo antes de la formación del imperio inka (ver p. ej. Bauer y Covey 2002).

Así, la adopción de este término, entre otros, debió provenir de la adopción de un hecho religioso básico, propio de los estados centralizados, la igualación del soberano con el sol. A esto se añadió -probablemente desde mucho antes de los inkas -como se ha anotado recientemente respecto a los datos de la crónica de Montesinos- la creación de una serie de títulos asociados a la mencionada una doble serie de cinco ancestros reales, cada uno con un título característico respectivo referente a su posición en la serie. Entre los inkas, la única de estas civilizaciones de la que tenemos fuentes etnohistóricas, todos los miembros de la realeza, empero la existencia de estos otros ancestros, decían descender de Manco Qhapaq, el primer y único ancestro reconocido de la realeza inka (ver por ejemplo la versión de Garcilaso de la Vega, él mismo miembro del denominado Qhapaq ayllu).

\section{El significado de manco en relación a la mitohistoria del ori- gen inka}

Avanzando más en el significado de este término, recurriremos ahora al conocido mito de origen de los inkas, en el cual los hermanos fundadores, los cuatro ancestros denominados Ayar -entre los que se encontraba Ayar Mancosalen de cuevas en un cerro sobre el pueblo de Paqaritampu, en el valle de 
Yaurisque, situado exactamente al sur del Cuzco. Este pueblo fue trasladado en temprano tiempo colonial al antiguo pueblo de Pumamarca, donde se conservan las cuevas rodeadas de estructuras inka (Bauer 1992, Urton 1994). Mientras una de las versiones más detalladas proviene de los informantes inka de Sarmiento de Gamboa (1572) y cuenta que ellos salieron de las cuevas de este pueblo, la versión de Garcilaso de la Vega cuenta que ellos salieron en realidad de la isla del Sol en el lago Titicaca, desde donde se dirigieron al mismo pueblo de Paqaritampu. De allí, como se sabe, en ambos mitos ellos viajaron siguiendo más o menos la ruta del río y valle del Yaurisque -al que propongo que podemos igualar en el mito con la Vía Láctea o mayu- hasta llegar al valle del Cuzco, convencer a sus habitantes originarios de ser Manco hijo del sol y elegir dicho valle -habitado por un protoestado que resistió el influjo Wari en la región- como lugar de asiento del nuevo estado.

Al momento de su ascensión al trono, la capital de este protoestado -entonces llamada Acamama- se transforma en el Cuzco y se refunda su templo solar. Este, llamado antes Indicancha -en referencia al pájaro indi, ave totémica que simbolizaba al sol-, pasa a llamarse Qorikancha, más en referencia a las riquezas del nuevo estado. Ayar Manco cambia su nombre precisamente a Manco Qhapaq, que resulta el título del primer rey de esta pseudodinastía en que organizaba su memoria histórica este estado llamado a dominar los Andes centrales.

Ambas versiones míticas -o mitohistóricas- así leídas, permiten identificar a Ayar Manco con el sol saliendo al amanecer del lago Titicaca y luego de Paqaritampu. De hecho, la palabra misma paqarina alude al origen tanto como el amanecer, como se deduce de numerosos lugares tomados como sitios de origen, algunos de los cuales tienen construcciones -muchas de ellas inkaque permiten ver el amanecer por ventanas desde dentro de habitaciones. Por otro lado, el gran lago del sur fue considerado por los inkas durante toda su historia -junto con Tiwanaku y la isla del sol- como un lugar de origen, y de ello da fuerte testimonio el hecho de que al final de la historia inka como entidad estatal independiente, Manco Inca eligió este nombre posiblemente como un nuevo inicio para la historia inca tras la derrota ante los españoles. Por ello fue hasta el lago para reentronizarse como rey sagrado y reactualizar el poder simbólico de su nombre. Luego, al fracasar su rebelión contra los invasores españoles, siguiendo la ruta del río sagrado Willkamayu o Vilcanota, se internó en la ciudad de Vilcabamba, posiblemente con la intención de gobernar bajo la figura del sol en el inframundo contenida en el nombre adoptado, presto a retornar en cualquier momento en un nuevo amanecer para los inkas. 


\section{Conclusión}

Las acepciones de manco como submundo, mundo inferior o lugar de diario recorrido y origen del sol al amanecer deben ser aplicadas a los contextos de los tres nombres en que fue utilizado por los inkas. En todos ellos el término alude tanto al agujero imaginario por donde emerge el sol como al submundo por donde este transita todas las noches en la cosmología de los pueblos sudamericanos. ${ }^{4}$ Así, Ayar Manco significaba 'el antepasado del submundo o de las profundidades' y no alude especialmente a su condición solar, sino aparentemente es el nombre que se refiere más al antepasado antes de su entronización como rey solar propiamente dicho.

Una vez fundado el Cuzco y entronizado rey, aparece el título real Manco Qhapaq, que puede traducirse "rico señor o rey de las profundidades o del submundo" -con referencia al sol y su espectacular brillo a punto de emerger de debajo de la tierra- puesto que Qhapaq quiere decir 'señor rico'. Este era un nombre aplicado a los reyes de menos de 40,000 hogares subordinados, a partir de los cuales recibían el título de Qhapaq apu en el sistema clasificatorio inka. El nombre de Manco Qhapaq es así anterior al desarrollo pleno del estado inka, puesto que después de la caída del imperio a manos de los españoles, Manco Inka adoptó este otro nombre, al que podemos traducir como "Inka de las profundidades o del submundo". Como dije, quería resaltar en contexto de la derrota ante los españoles su condición de Sapa Inka y para su nuevo comienzo de la historia inka no usó el título de menos importancia de Qhapaq. Estos significados son los que, me parece, articulan mejor toda la evidencia aportada en este trabajo. Esto también permite entender por qué no había contradicción alguna en la nobleza o Qhapaq ayllu entre proclamarse descendientes tanto del sol como de Manco Qhapaq y Garcilaso ni se preocupa en aclararlo.

Por otro lado, el uso del término manco en tal diversidad de contextos no debe extrañar, aunque haya llevado a diversidad de hipótesis sobre su significado por los etnohistoriadores, pues es más bien dependiente de ideas conectadas entre sí en la cosmología en que se basaba la religión solar de los inkas. Los pueblos tradicionales relacionan -como estudió Gerardo ReichelDolmatoff entre los tukano del Vaupés colombiano- palabras que a primera vista nos pueden parecer muy laxa o confusamente relacionadas y que desde el pensamiento occidental no podríamos registrar en un diccionario normal. Respecto a la Vía Láctea, un concepto necesariamente asociado a las cosmologías sudamericanas, este autor austríaco-colombiano anotaba:

$4 \quad$ No tocamos aquí el interesante asunto de las transformaciones míticas que experimentaba el sol en este su diario camino nocturno, que podemos extraer de la iconografía y de la mitología comparada.

LETRAS 85 (122), 2014 
En la ideología tukana [...] las imágenes simbólicas son vistas siempre como una cadena de analogías. Por ejemplo, la Vía Láctea puede ser conceptualizada como un río, un camino en la selva, un inmenso grupo de gente marchando, una piel de serpiente desprendida, una corriente fertilizadora de semen, y así sucesivamente (1982:170, mi traducción).

En este sentido es interesante que la acepción contemporánea de manco recogida el 2005 provenga precisamente de una hablante quechua y de una región al sur del Cuzco como como Cangallo, Ayacucho, y que ella especificara bien que el hueco a que se refiere la expresión manco es uno grande, como para cosechar tubérculos $-\mathrm{y}$, añadiríamos nosotros mitográficamente, incluso para que emerja el sol del inframundo- y no un agujero pequeño al que aludió con el término más común de $u k u$, o uchku.

\section{Referencias bibliográficas}

ARANA BUSTAMANTE, Luis (2010) 'Sin malicia ninguna...' Transformación indígena colonial y estrategias sociales y culturales en un kuraka ilegítimo (Huaylas, 1647-48). Lima: Asamblea Nacional de Rectores.

BAUER, Brian (1996) El desarrollo del estado Inka. Cuzco: CERA "Bartolomé de las Casas". BAUER, Brian y Alan COVEY (2002) "Processes of State Formation in the Inca Heartland (Cuzco, Peru)”. American Anthropologist 104(3);pp.846-864.

BERTONIO, Ludovico ([1612]1984) Vocabulario de la Lengua Aymara. Reedición de la edición facsimilar publicada en 1956. Introducción de Xavier Albó y Félix Layme, ix- lviii. La Paz: Centro de Estudios de la Realidad Social, Museo Nacional de Etnografía y Folklore e Instituto Francés de Estudios Andinos.

GARCILASO DE LA VEGA, Inca ([1609]1943) Comentarios Reales de los Incas. 2 v. Edición de Ángel Rosenblat. Buenos Aires: Emecé.

GONZÁLES HOLGUÍN, Diego ([1608] 1989) Vocabulario de la lengua general de todo el Perú Ilamada Lengua Qquichua o del Inca. Edición facsimilar de la versión de 1952, con addenda. Lima: Universidad Nacional Mayor de San Marcos.

GUAMAN POMA DE AYALA, Felipe, c.(1615) El Primer Nueva Corónica y Buen Gobierno. Edición digital completa en Internet por la Biblioteca Real de Copenhague a cargo de Rolena Adorno, con estudios, índices temáticos, gráficos y material documental relacionado. Disponible en www.kb.dk/elib/maa/poma.

GUAMAN POMA DE AYALA, Felipe ([c.1615]1980) El Primer Nueva Corónica y Buen Gobierno. Edición crítica de John Victor Murra y Rolena Adorno. Traducción de los textos andinos de Jorge Urioste. México D.F.: Siglo XXI Editores.

REICHEL-DOLMATOFF, Gerardo (1982) "Astronomical models of social behaviour among some Indians of Colombia". Annals of the New York Academy of Sciences 385:pp.165-181.

SALOMON, Frank (1991) "The "Beautiful Grandparents": Andean Ancestor Shrines and Mortuary Ritual as seen through Colonial Records" en Tom D. Dillehay, ed., Tombs for the living: Andean Mortuory Practices. Washington D.C.: Dumbarton Oaks Research Library and Collection; pp. 315-353. 
SARMIENTO DE GAMBOA, Pedro ([1572]1942) Historia índica. Edición de Ángel Rosenblat. Buenos Aires: Emecé.

URTON, Gary (1994) Historia de un mito. Cuzco: CERA "Bartolomé de las Casas"

ZUIDEMA, R. Tom ([1972]1989) "Significado en el arte Nazca. Relaciones iconográficas entre las culturas Inca, Huari y Nasca en el sur del Perú" en Reyes y Guerreros. Ensayos de cultura andina, Lima: Fomciencias; pp. 386-401.

ZUIDEMA, R. Tom (1978) "Jerarquía y espacio en la organización social incaica” en Estudios Andinos 8 (14) Lima: Universidad del Pacífico pp.5-27,

ZUIDEMA, R. Tom ([1980]1989) “El parentesco inca: una nueva visión teórica” en Reyes y guerreros. Ensayos de cultura andina. Lima: Fomciencias; pp. 54-116

ZUIDEMA, R. Tom ([1986]1991). Inka civilization at Cuzco. Austin: Texas University Press. 
